\title{
Heavy metal and PCB spatial distribution pattern in sediments within an urban catchment - contribution of historical pollution sources
}

\author{
Celia Dias-Ferreira ${ }^{1,2}$ (D) - Rosinda L. Pato ${ }^{1}$. Jorge B. Varejão ${ }^{1} \cdot$ Alexandre O. Tavares $^{3}$. \\ Antonio J. D. Ferreira ${ }^{1}$
}

Received: 31 January 2016 / Accepted: 29 August 2016

(C) Springer-Verlag Berlin Heidelberg 2016

\begin{abstract}
Purpose This work analyzes polychlorinated biphenyl (PCB) and heavy metal contamination in fluvial sediments and soils in an urban catchment, according to the geo-accumulation index and to soil and sediment quality guidelines. The catchment is located in Coimbra, Portugal, being affected by frequent flooding, and its main stream is a tributary to one of the major rivers in Portugal (Mondego). Given the presence of industrial activities over time, some inputs of pollutants are expected, but so far, the legacy of historic pollution in this catchment has not yet been investigated.

Materials and methods Twenty-five samples were collected from nine sampling sites at the depths of 0-20, 20-40 and 40$60 \mathrm{~cm}$ (to provide a historic perspective) along longitudinal profiles (streamlines) and in soils downstream of pollution sources. These samples were analyzed for six heavy metals $(\mathrm{Cu}, \mathrm{Cr}, \mathrm{Pb}, \mathrm{Cd}, \mathrm{Zn}, \mathrm{Ni})$, organic carbon, $\mathrm{pH}$ and ten PCBs (IUPAC numbers 28, 30, 52, 101, 138, 153, 166, 180, 204, 209).

Results and discussion Total PCB concentrations ranged $0.47-5.3 \mathrm{ng} \mathrm{g}^{-1}$ dry weight (dw), and levels increase from
\end{abstract}

Responsible editor: Saskia Keesstra

Celia Dias-Ferreira

celia@esac.pt

1 Research Centre for Natural Resources, Environment and Society (CERNAS), College of Agriculture, Polytechnic Institute of Coimbra, Bencanta, 3045-601 Coimbra, Portugal

2 Materials and Ceramic Engineering Department CICECO, University of Aveiro, Campus Universitário de Santiago, 3810-193 Aveiro, Portugal

3 Centre for Social Studies and Earth Sciences Department, University of Coimbra, Rua Sílvio Lima, Pólo II, 3030-790 Coimbra, Portugal the bottom to the top layers, suggesting an increased input over the last 100 years. PCB congener distribution shows the dominance of hexachlorobiphenyls, especially PCB138, suggesting the existence of local sources. PCB levels did not exceed sediment quality levels, placing sediments/soil under class 1 (not contaminated) or class 2 (trace contamination) with respect to $\mathrm{PCB}$. All six metals exceeded the lowest effect level for sediment quality criteria, and three $(\mathrm{Cd}, \mathrm{Pb}$ and $\mathrm{Zn})$ largely exceeded the clean levels for dredged materials, placing sediments in class 5 (heavily contaminated). Sampling site $\mathrm{S} 1$ presented the highest concentrations of $\mathrm{Zn}, \mathrm{Pb}$ and $\mathrm{Cd}$, and historic vehicle traffic was identified as the most likely source, given the vertical and horizontal profiles.

Conclusions High levels of $\mathrm{Pb}, \mathrm{Cd}$ and $\mathrm{Zn}$ were found in fluvial sediments at some locations of the Loreto catchment, likely from historic traffic sources. This urban area is frequently affected by flooding events and is currently being subject to urban redevelopment. During these events/actions, historic pollutants in the sediments might surface and be redistributed, impacting the downstream ecosystem of the major Mondego River or increasing the risk of exposure of the urban population.

Keywords Heavy metals $\cdot$ Historic pollution $\cdot \mathrm{Pb} \cdot \mathrm{PCB}$. River sediments $\cdot$ Traffic emissions

\section{Introduction}

Urban soils generally show greater contamination levels than rural sites due to their proximity to pollution sources. New tools and policies on urban management and planning have led to significant changes in land use in cities in the last decades and polluting activities that once integrated urban scenarios have been moved further away. However, previously 
released pollutants may still be found within city limits, especially if bond to sediments in urban streams or lakes. Polychlorinated biphenyls (PCBs) and heavy metals are two groups of pollutants extensively referred in the bibliography as resulting from anthropogenic activities which are found associated with sediments (Desmet et al. 2012; Zhang et al. 2016; Guan et al. 2016).

PCBs are a group of synthesized organic compounds having 209 congeners with chlorine atoms at different positions on two benzene rings. They have been used in a wide variety of applications since the late 1920s, when they first started to be synthesized, including as dielectrics in transformers and large capacitors; as heat exchange fluids; and as additives in paints, in carbonless copy paper and in plastics. PCBs are classified as persistent organic pollutants (POPs) and in the environment are found strongly adsorbed to soils and sediments, bioconcentrating in the food chain (Gomes et al. 2015). Generally, their water solubility and vapour pressure decrease with increasing chlorination. After incidents in Japan (contamination of rice oil by PCB) in 1968 and in Taiwan in 1979, a large number of people were exposed to PCB and the effects of these compounds on human health became known, creating awareness. Because of their teratogenic, immunogenic and probable carcinogenic health effects (ATSDR 2000) and persistent nature, $\mathrm{PCB}$ production has been banned since the late 1970s. However, PCB can still be found today in PCB-containing old electric equipment, still in use or in storage.

Heavy metals, represented by metallic elements with relatively high density - $\mathrm{Cd}, \mathrm{Cr}, \mathrm{Cu}, \mathrm{Pb}, \mathrm{Zn}, \mathrm{Hg}$, Ni and As - can have different sources in the environment, from geological background, industrial or agricultural activities, domestic effluents and atmospheric sources. The environmental pollution contamination and human exposure result mainly from anthropogenic activities such as mining and smelting operations, industrial production and use, domestic and agricultural use of metals and metal-containing compounds, or road traffic emissions and deposition of dust and aerosols (Lee et al. 2006; Kachenko and Singh 2006; Shafie et al. 2014). In the last decades, there has been an increased ecological and global public health concern associated with environmental contamination by heavy metals, related with their toxicity and their inter-relation and association with metalloids but also their reactivity and oral bioaccessibility (Manta et al. 2002; Guo et al. 2012; Tchounwou et al. 2012; Rodrigues et al. 2013).

The Agency for Toxic Substances \& Disease Registry Substance Priority List (ATSDR 2016) ranks contaminants in the environment according to their order of relevance. In this list, $\mathrm{Pb}$ ranks 2nd, $\mathrm{PCB}$ ranks 5th, Cd ranks 7 th, Ni ranks 57th, $\mathrm{Zn}$ ranks 75 th, $\mathrm{Cr}$ ranks 78 th, and $\mathrm{Cu}$ ranks 118 th. Several countries have quality criteria for total PCB and heavy metals in soils and sediments. The Ontario quality criteria for sediments (MEE 1997) refers $70 \mathrm{ng} \mathrm{g}^{-1}$ dry weight as the lowest effect level for PCB, while in Denmark, the limit for soil quality is $20 \mathrm{ng} \mathrm{g}^{-1}$ total PCB (Gomes et al. 2015). The Portuguese regulation (DR 1995) also classifies dredged sediments according to the sum of seven PCB congeners $(28,52$, $101,118,138,153$ and 180). Table 1 compiles these quality criteria for both PCB and heavy metals.

During large storm events and related flooding, sediments accumulated in urban environment are redistributed inside the urban area or are transported out of the catchment, carrying along pollutants. Impacts on downstream ecosystems are not negligible: Sandahl et al. (2007) showed that the sensory physiology and predatory avoidance behaviour of juvenile Pacific salmon were significantly impaired by $\mathrm{Cu}$ at concentrations as low as $2 \mu \mathrm{g} \mathrm{L}^{-1}$ and, that after storm events, $\mathrm{Cu}$ levels largely exceed this value (varying from 3.4 to $64.5 \mu \mathrm{g} \mathrm{L}^{-1}$ ) due to storm water inflow. This is an emerging concern for many populations of threatened and endangered Pacific salmon that spawn and rear in coastal watersheds and estuaries and one of many examples of the possible impacts on the aquatic ecosystems of storm water runoff and flooding. In addition, in catchments with distinct mosaics of urban and
Table 1 Quality guidelines for heavy metals and PCB

\begin{tabular}{|c|c|c|c|c|c|c|}
\hline & \multirow[t]{2}{*}{$\begin{array}{l}\text { Lowest effect level } \\
\text { (MEE. 1997) }\end{array}$} & \multicolumn{5}{|c|}{$\begin{array}{l}\text { Classification of dredged sediments according to the level of } \\
\text { contamination (DR 141/1995) }\end{array}$} \\
\hline & & Class 1 & Class 2 & Class 3 & Class 4 & Class 5 \\
\hline $\mathrm{Cd}\left(\mathrm{mg} \mathrm{kg}^{-1}\right)$ & 0.6 & $<1$ & $1-3$ & $3-5$ & $5-10$ & $>10$ \\
\hline $\mathrm{Cr}\left(\mathrm{mg} \mathrm{kg}^{-1}\right)$ & 26 & $<50$ & $50-100$ & $100-400$ & $400-1000$ & $>1000$ \\
\hline $\mathrm{Cu}\left(\mathrm{mg} \mathrm{kg}^{-1}\right)$ & 16 & $<35$ & $35-150$ & $150-300$ & $300-500$ & $>500$ \\
\hline $\mathrm{Pb}\left(\mathrm{mg} \mathrm{kg}^{-1}\right)$ & 31 & $<50$ & $50-150$ & $150-500$ & $500-1000$ & $>1000$ \\
\hline $\mathrm{Ni}\left(\mathrm{mg} \mathrm{kg}^{-1}\right)$ & 16 & $<30$ & $30-75$ & $75-125$ & $125-250$ & $>250$ \\
\hline $\mathrm{Zn}\left(\mathrm{mg} \mathrm{kg}^{-1}\right)$ & 120 & $<100$ & $100-600$ & $600-1500$ & $1500-5000$ & $>5000$ \\
\hline PCB (ng g $\left.{ }^{-1}\right)$ & 70 & $<5$ & $5-25$ & $25-100$ & $100-300$ & $>300$ \\
\hline
\end{tabular}

Class 1 - clean; class 2-trace contamination; class 3-slight contamination; class 4 - contamination; class 5heavy contamination 
non-urban land uses, the connectivity between runoff and pollutant sources and water resources is still a research challenge (Ferreira et al. 2016b). Another situation in which pollutants accumulated in sediment might be of concern is in case of urban redevelopment. Even though sediment accumulation areas are not generally used as residential areas, they are most attractive for the development of urban park and leisure areas, where children play and which other city dwellers regularly use (for jogging, for instance), increasing the risk of exposure of the urban population to historic pollutants. Nonetheless, much more research so far has focused on global background levels than on populated locations, with only a few studies existing on urban-residential soil PCB levels (Cachada et al. 2009; Martinez et al. 2012).

We examined polychlorinated biphenyl (PCB) and heavy metal levels in sediments and residential soil from the Loreto catchment, Central Portugal, with an area of $2.6 \mathrm{~km}^{2}$. Despite its small size, Loreto is an important catchment due to its location inside the city of Coimbra and with the Loreto stream, a tributary of the major Mondego River, being affected by constant flooding. The stream has also been subject to several construction works, such as piping, constructed margins and building of city parks along its margins. There are no records of intensive use, production or disposal sites of PCB nor heavy metals in this area, but given that this is an urban and industrial catchment with a comparatively high percentage of industrial areas in the city of Coimbra, some inputs of pollutants are expected. The legacy of historic pollution in this catchment has not yet been investigated.

This work aims at discussing PCB and heavy metal concentrations in soils and sediments at the Loreto catchment as a result of anthropogenic sources. The work starts with an inventory of emission sources of these contaminants in the catchment. Based on the preliminary screening, a sampling site located near a large PCB emission source was selected, together with one background site and one sediment accumulation area. For heavy metals, two sources were identified: one is a line source (main road), which crossed at the mouth of the catchment, and the second is a ceramic factory, which was located $200 \mathrm{~m}$ from the first source. Since both sources are located close together, sampling sites were selected along a longitudinal in order to assess how sediment contamination decreases with increasing distance to emission sources.

Considering the changes in land use and urban development that took place within the catchment in last decades (the transit between Porto and Lisbon was diverted to a motorway type road built at some distance, closing of the ceramic factory) and also technological changes (e.g., lead stopped being added to gasoline in early 2000s), it is also our aim to assess if the emissions from these past sources are still present within the catchment and to propose mitigation measures to prevent these contaminants from affecting human health and ecosystems in the future.

\section{Materials and methods}

\subsection{Study site description}

The study area is located in the Central Region of Portugal, $35 \mathrm{~km}$ far from the Atlantic coast, and represents a right bank small catchment of the river Mondego at the northern part of the old town of Coimbra.

From a geological perspective, the substratum of the Loreto catchment is represented by Jurassic dolomitic and marly limestones, covered by Plio-Quaternary arenaceous, and pelitic alluvial materials, with sandy and peat bodies. The morphological characteristics present, in general, lower slopes, under $8 \%$ at the upstream, with a top hypsometric $132-\mathrm{m}$ value, and moderate hill slopes framing the stream at the downstream ( 8 to $35 \%$ ) with a lower hypsometric point with $18 \mathrm{~m}$, where the NNE-SSW guidance of the downstream valley reflects a tectonic orientation (Tavares 1999).

The area has moist Mediterranean climate characteristics, with over $60 \%$ of the precipitation falling in the period November to March, with dominant mixed forest with shrubs and herbaceous associations in the catchment area and riparian species and grass in the lower downstream valley. The Loreto hydrological basin presents a perennial terminal streamline, with an upstream intermittent regime, characterized by little or no flow in the summer and frequent occurrences of winter and spring floods. The area presents a general water potential recharge of about $10 \%$ and a hydraulic conductivity between $10^{-7}$ and $10^{-11} \mathrm{~m} \mathrm{~s}^{-1}$.

The area showed deep changes in land use and occupation from the last 50 years, from a rural area with poor agriculture with a few residential or commercial buildings along the main roads to an area with large residential occupation on the top of the hills or in the valley, and two large commercial and industrial plots.

The actual land use occupation, of which approximately one quarter is residential areas, $10 \%$ is industrial or commercial, about $55 \%$ is forest and other semi-natural or agricultural areas, and $10 \%$ is represented by road infrastructures or other anthropic occupation, can be observed in Fig. 1, resulting from photointerpretation and classification of 2012 satellite imagery. The former Master Plan, dating from the 1950s, considered the area a rural zone which supplied fresh air and agricultural produce. Urban occupation begins to develop in an informal way from the 1960s, which later joined neighbourhoods to workers from nearby industrial areas. Small industrial blacksmithing and metalwork units came to develop, as well as some quarries of limestone. From 1980, there was a rapid urban expansion with new neighbourhoods, and the Master Plan 1994 was responsible for the present urban fabric, the development of plots for industry and commerce, and the road infrastructure. 

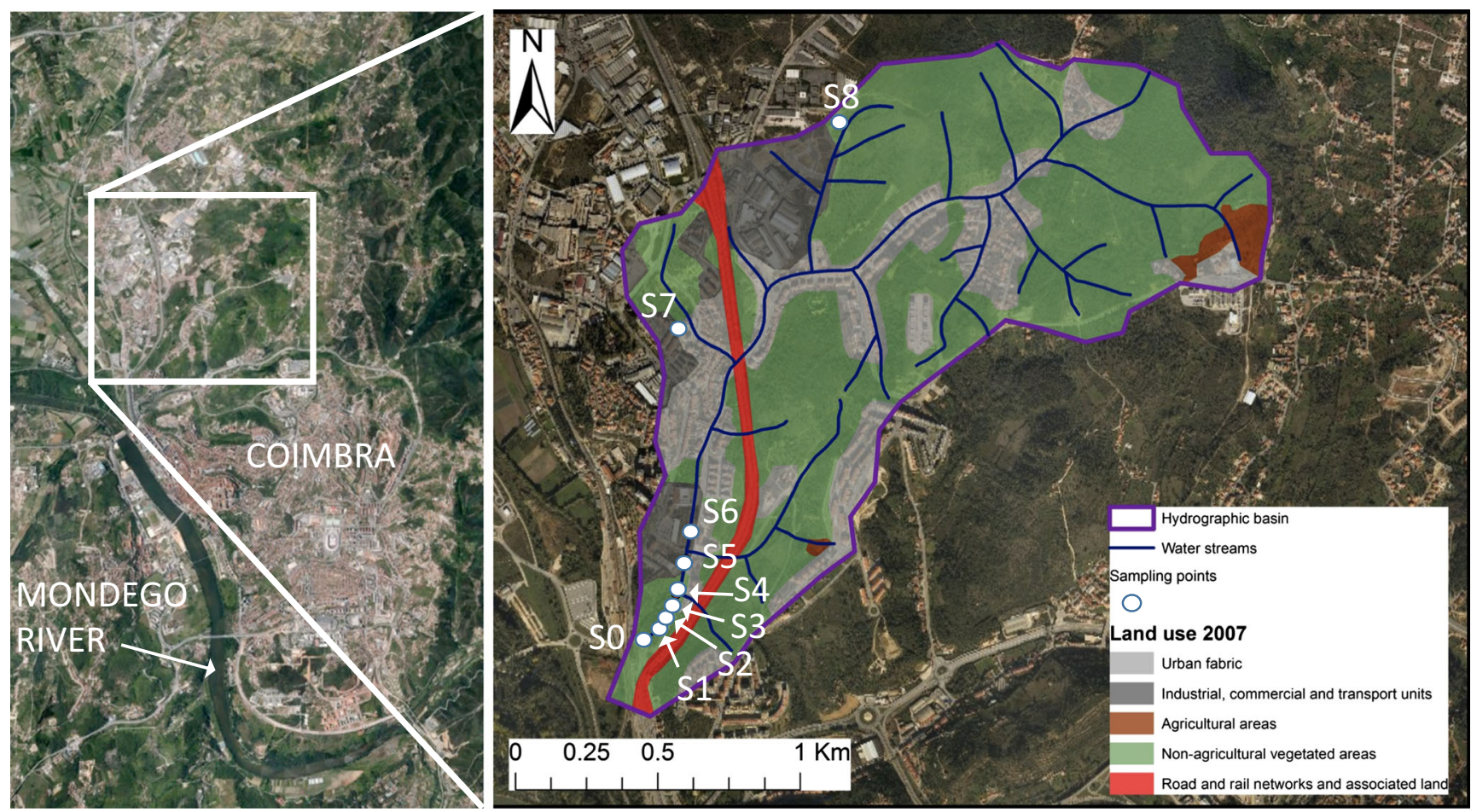

Fig. 1 Mondego River and the city of Coimbra (on the left pane); Loreto catchment, with sampling points ( $\mathrm{S} 0-\mathrm{S} 8)$ and land use (right pane) $\left(40^{\circ} 15^{\prime}\right.$ $\left.08.48^{\prime \prime} \mathrm{N}, 8^{\circ} 27^{\prime} 10.72^{\prime \prime} \mathrm{W} ; 40^{\circ} 13^{\prime} 14.41^{\prime \prime} \mathrm{N}, 8^{\circ} 24^{\prime} 37.79^{\prime \prime} \mathrm{W}\right)$

\subsection{Sampling strategy}

All pollutants emitted to the soil and water in the catchment eventually make their way downwards, towards the mouth of the catchment, either dissolved in the water or dragged adsorbed to particulate material. Sediment accumulation areas downstream of the catchment thus provide both a spatial as well as a time-integrated perspective of pollutant emission across the catchment, which is useful for this work.

Assessment of the level of contaminants with time was carried out by collecting sediments at different depths from sampling site S0 (Fig. 1). Site S0 is a downstream sediment accumulation area near the mouth of the catchment. This site has remained undisturbed from human action for the last century and is located on the stream floodplain. During flooding, the area is filled with water and suspended sediments from upstream. The decrease of water speed as it sprawls through the floodplain allows for the sedimentation of suspended material transported by the flood, which is trapped and accumulates at the specific site where the samples were taken. Hence, S0 was considered representative of an alluvial sediment deposition and used in the context of this work to provide an overall time and spatial integrated perspective of contaminants in the catchment. Because the site has been free from direct human intervention and because of the hydrological characteristics of the site described above, we assume that the layer of sediments deposited over the years will directly correspond to the age of these sediments, with the deepest layers corresponding the sediments deposited earlier. Since we do not have information on sedimentation rates, only a rough correspondence can be made between the depth of the sediment column and its age. We further assume that there is a correspondence between the concentration of contaminants in a given sediment layer and the emissions occurring at the time of deposition. This assumption holds better for air-dispersed contaminants that reach the sediment, while a time gap does exist between the moment of soil erosion upstream and the moment when that eroded particle reaches the mouth of the catchment. However, we have assumed the time gap to be negligible given the small size of the catchment. In short, we considered that a rough correspondence can be made between depth, sediment age and contaminant input. In this study, sampling took place at three depths: $0-20,20$ to 40 and $40-60 \mathrm{~cm}$ below the surface.

In this context, there is a major difference between the heavy metals that are airborne, from two specific sources (the ceramic factory and the one that was, for decades until the 1990s, the busiest road in Portugal, which was located at the catchment mouth), and the PCBs that were transported from the numerous electric transformation plants, which spread throughout the catchment area and were mainly transported adsorbed to sediments during extreme rainfall events.

In addition to S0, other downstream locations were also sampled to assess the spatial distribution of contaminants. The strategy consisted in sampling at regular intervals 
(50 m) starting from S1, along the Loreto stream, covering a linear distance of approximately $300 \mathrm{~m}$ (sampling sites S1 to S6). For these locations, there were two heavy metal emission sources nearby, one road and one ceramic factory (as explained above). For PCB assessment, a sample was collected at sampling site $\mathrm{S} 7$, which is located immediately downstream an electric transformation station (high-to-medium voltage). This facility was identified as the only probable major point source for this contaminant in the catchment.

In order to assess if the contaminant levels measured in the sampling sites $\mathrm{S} 0-\mathrm{S} 7$ are elevated, a background reference sample was collected from sampling site $S 8$, an area at the upper level of the catchment, not disturbed by local human activities, and covered with spontaneously occurring vegetation (shrubs and grasses).

In total, 25 samples of sediments and soil were collected from nine sampling sites in the first half of 2012 from different locations inside the catchment, as summarized in Table 2.

\subsection{Sampling procedure}

Prior to sample collection, overlying vegetation and other debris were removed. Sediment samples (S0-S6) were collected using a hand-held coring device at three depths $(0-20,20-40$ and $40-60 \mathrm{~cm}$ ) in order to quantify the presence of contaminants from a historical perspective. Soil samples (S7 and S8) were also collected: at S7, the soil was stony and very compact, so collection was carried out with a small shovel after digging a small trench that gave direct access to all three layers. At S8, only the superficial layer was collected using a shovel, since the soil layer was thin at this point, with the bed rock close to the surface. Table 2 summarizes this information.

After collection, each sample was split into three subsamples according to the target contaminants and to the analytical procedures that followed: $\mathrm{pH}$, water content (in soil samples), organic matter, metal concentrations (copper, zinc, cadmium, nickel, chromium and lead) and PCB concentration. Subsample 1 was used to measure the water content; subsample 2 was stored in a plastic container and used for determination of heavy metals $(\mathrm{Cu}, \mathrm{Cr}, \mathrm{Pb}, \mathrm{Cd}, \mathrm{Zn}, \mathrm{Ni})$, organic carbon and $\mathrm{pH}$; subsample 3 was stored in a glass container and was analyzed for ten PCB congeners (IUPAC numbers 28, 30, 52, 101, 138, 153, 166, 180, 204, 209). Except for PCB 30, 166 and 204, these PCB congeners are all frequently detected worldwide and are among the most prominent in commercial PCB mixtures as well as being less susceptible to environmental degradation. PCB analysis was carried out only in samples from S0, S7 and S8, while the heavy metal determination was carried out in all samples. After collection, samples were transported to the laboratory under refrigerated conditions and kept at $4{ }^{\circ} \mathrm{C}$ until analysis.

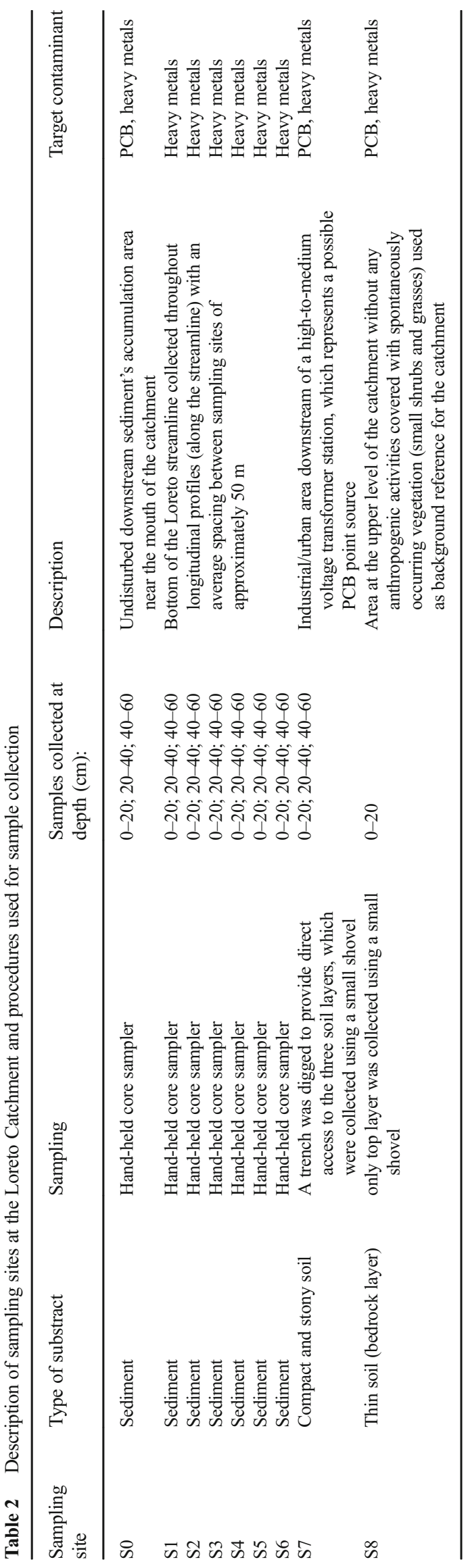




\subsection{Analytical procedures (except PCB analysis)}

Water content (expressed as percentage of the initial mass) was determined by the loss of mass after drying at $105{ }^{\circ} \mathrm{C}$ (three replicates). $\mathrm{pH}$ was measured in a suspension of the dried sample in distilled water, at a solid/liquid ratio of 1:2.5 (in duplicate). Organic carbon was determined in the fraction $<2 \mathrm{~mm}$ by combustion at $590{ }^{\circ} \mathrm{C}$ followed by infrared detection, using the LECO Dual Range Sulfur and Carbon Analysis System, mod. SC-144 DR, and the organic matter was calculated multiplying organic carbon by the factor 1.72 (LQARS 1977). The fraction $<2 \mathrm{~mm}$ was further ground to $<150 \mu \mathrm{m}$ and digested using aqua regia (ISO 1995, 1998), and copper, zinc, cadmium, nickel, chromium and lead were measured on the extracted solution using atomic absorption spectroscopy (AAS). The method detection limits (DLs) for metals are $0.022 \mathrm{mg} \mathrm{kg}^{-1}$ for $\mathrm{Cu}, 0.010 \mathrm{mg} \mathrm{kg}^{-1}$ for $\mathrm{Cd}$, $0.154 \mathrm{mg} \mathrm{kg}^{-1}$ for $\mathrm{Pb}, 0.039 \mathrm{mg} \mathrm{kg}^{-1}$ for $\mathrm{Ni}, 0.022 \mathrm{mg} \mathrm{kg}^{-1}$ for $\mathrm{Cr}$ and $0.005 \mathrm{mg} \mathrm{kg}^{-1}$ for $\mathrm{Zn}$.

\subsection{PCB analysis}

\subsubsection{Chemicals and solvents}

PCB standards were of analytical grade, obtained from Fluka, Sigma-Aldrich (PCB28, 52, 101, 138, 153, 180 and 209) and Ultrascientific (PCB30, PCB65 and PCB204). The solvents hexane and acetone were Pestinorm (VWR BDH Prolabo). Hydrochloric (37.6 \%), nitric (65\%) and sulphuric (95-7\%) acids were of trace metal grade. Anhydrous $\mathrm{Na}_{2} \mathrm{SO}_{4}, \mathrm{KMnO}_{4}$, $\mathrm{NaCl}$ and silica gel (silicic acid) were of lab grade. Silica gel was cleaned up before use according to the USEPA method 3630C. The water was deionized with a Milli-Q plus system from Millipore (Bedford, MA, USA).

\subsubsection{Procedure}

For PCB analysis, the soil extraction method used was the USEPA method $3550 \mathrm{C}$, in which $10 \mathrm{~g}$ of soil was extracted with $3 \times 30 \mathrm{~mL}$ of acetone-hexane $(1: 1)$ in a glass vial by ultrasonication $(20 \mathrm{kHz})$ for 60 min using Retsch, model UR1, $35 \mathrm{kHz}, 240 \mathrm{~W}$. After vacuum filtration and concentration, the extracts were cleaned following the USEPA methods 3665A and $3630 \mathrm{C}$. The PCB congeners were analyzed by gas chromatography (GC) with an ECD detector (HP 6890 Series, Hewlett-Packard, Palo Alto, CA, USA). The column used was a TRB-5-MS with $30 \mathrm{~m} \times 0.25 \mathrm{~mm}$ i.d. and $0.25-\mu \mathrm{m}$ film thickness (Phenomenex, Torrance, CA, USA). The oven temperature was programmed starting at $70{ }^{\circ} \mathrm{C}$ for $2 \mathrm{~min}$, increased to $150{ }^{\circ} \mathrm{C}$ at a rate of $25^{\circ} \mathrm{C} \mathrm{min}^{-1}$ and then increased $4{ }^{\circ} \mathrm{C} \mathrm{min}^{-1}$ to $200^{\circ} \mathrm{C}$ and $8{ }^{\circ} \mathrm{C} \mathrm{min}^{-1}$ to $280^{\circ} \mathrm{C}$, where it holds for 4 min and finally $10^{\circ} \mathrm{C} \mathrm{min}^{-1}$ to $300^{\circ} \mathrm{C}$, where it holds for 2 min Pure helium was used as the carrier gas. The injector was operated in splitless mode ( $45 \mathrm{~s})$, and its temperature was $260{ }^{\circ} \mathrm{C}$. The injections of $1.0 \mu \mathrm{L}$ were performed manually. Data acquisition was performed using the Hercules Lite Chromatography Interface Software Jasco-Borwin version 5.1 .

The quantification was done using the internal standard calibration curve method according to the USEPA method 8000B. Each analysis was performed in triplicate, and the relative standard deviations (RSD) were all below $20 \%$. Blanks covering the entire analytical procedure (from the extraction to GC analysis) were analyzed and did not reveal any PCB contamination. Additionally, the mixed standards with known amount of the three PCB congeners (PCB30, PCB166 and PCB204) were spiked to the soil before extraction for the assessment of recovery rates. Average percentage recovery for the individual PCB congeners varied from 72 to $101 \%$ (PCB30), 77 to $121 \%$ (PCB65) and 80 to $132 \%$ for PCB204.

\subsection{Geo-accumulation index}

The geo-accumulation index I-geo, described by Muller in 1969, was applied to assess the impact of heavy metals and PCB in the environment, in line with the procedure followed in a previous work by Trujillo-González et al. (2016). I-geo value was computed as follows:

$\mathrm{I}-$ geo $=\log _{2}[$ concentration of the pollutant $/(1.5 \times$ background value $)]$

The factor 1.5 in the formula refers to the variation of background values caused by the environment (TrujilloGonzález et al. 2016). Background values used in the calculation of I-geo values were those obtained in sampling site S8.

Interpretation of I-geo value leads to the following seven categories: "unpolluted" for I-geo $\leq 0$, "unpolluted to moderately polluted" for $0<\mathrm{I}$-geo $<1$, "moderately polluted" for $1<$ I-geo $<2$, "moderately polluted to highly polluted" for $2<$ I-geo $<3$, "highly polluted" for $3<$ I-geo $<4$, "highly to extremely polluted" for $4<$ I-geo $<5$ and "extremely polluted" for I-geo $\geq 5$ (Trujillo-González et al. 2016).

\section{Results}

The characterization of collected samples is presented in Table 3 for $\mathrm{pH}$, organic matter, water content, metal levels and total PCB. Geo-accumulation values (I-geo) are also presented.

The vertical and horizontal distributions of total PCBs are represented in Fig. 2, whereas Fig. 3 shows the relative percentage of each PCB congener for each sample/location.

The longitudinal profile of each heavy metal is represented in Fig. 4. In this figure, the levels measured at different depths at each sampling site along the Loreto stream are represented 
Table 3 Characterization of samples and geo-accumulation index

\begin{tabular}{|c|c|c|c|c|c|c|c|c|c|c|c|c|c|c|c|c|c|}
\hline \multirow[t]{2}{*}{ Site } & \multirow{2}{*}{$\begin{array}{l}\text { Depth } \\
(\mathrm{cm})\end{array}$} & \multirow[t]{2}{*}{$\mathrm{pH}$} & \multirow{2}{*}{$\begin{array}{l}\text { Org. matter } \\
(\%)\end{array}$} & \multicolumn{7}{|c|}{ Concentrations of metals $(\mathrm{mg} / \mathrm{kg})$ and PCB $(\mu \mathrm{g} / \mathrm{kg})$} & \multicolumn{7}{|c|}{ Geo-accumulation index I-geo } \\
\hline & & & & $\mathrm{Cu}$ & $\mathrm{Cd}$ & $\mathrm{Pb}$ & $\mathrm{Ni}$ & $\mathrm{Cr}$ & $\mathrm{Zn}$ & $\Sigma \mathrm{PCB}$ & $\mathrm{Cu}$ & $\mathrm{Cd}$ & $\mathrm{Pb}$ & $\mathrm{Ni}$ & $\mathrm{Cr}$ & $\mathrm{Zn}$ & $\Sigma \mathrm{PCB}$ \\
\hline \multirow[t]{3}{*}{ S0 } & $0-20$ & 7.2 & 5.93 & 73 & 3.46 & 261 & 31 & 32 & 227 & 5321 & 1.4 & 1.5 & 1.9 & -1.1 & -1.1 & 0.3 & 2.9 \\
\hline & $20-40$ & 7.2 & 5.47 & 71 & 3.23 & 245 & 27 & 29 & 216 & 3158 & 1.3 & 1.4 & 1.8 & -1.3 & -1.3 & 0.2 & 2.2 \\
\hline & $40-60$ & 7.1 & 3.35 & 35 & 1.69 & 103 & 31 & 63 & 162 & 960 & 0.3 & 0.5 & 0.5 & -1.1 & -0.1 & -0.2 & 0.4 \\
\hline \multirow[t]{3}{*}{$\mathrm{S} 1$} & $0-20$ & 7.4 & 4.81 & 67 & 9.03 & 476 & 35 & 43 & 1024 & - & 1.2 & 2.9 & 2.8 & -0.9 & -0.7 & 2.4 & - \\
\hline & $20-40$ & 7.5 & 8.89 & 79 & 19.50 & 788 & 32 & 38 & 1466 & - & 1.5 & 4.0 & 3.5 & -1.0 & -0.9 & 3.0 & - \\
\hline & $40-60$ & 7.7 & 2.85 & 32 & 2.93 & 127 & 41 & 51 & 272 & - & 0.2 & 1.3 & 0.8 & -0.7 & -0.4 & 0.5 & - \\
\hline \multirow[t]{3}{*}{$\mathrm{S} 2$} & $0-20$ & 7.5 & 6.69 & 71 & 1.73 & 92 & 29 & 34 & 344 & - & 1.3 & 0.5 & 0.4 & -1.2 & -1.0 & 0.9 & - \\
\hline & $20-40$ & 7.7 & 2.07 & 60 & 1.23 & 52 & 19 & 21 & 187 & - & 1.1 & 0.0 & -0.4 & -1.8 & -1.7 & 0.0 & - \\
\hline & $40-60$ & 7.8 & 1.58 & 43 & 1.73 & 74 & 21 & 24 & 199 & - & 0.6 & 0.5 & 0.1 & -1.6 & -1.5 & 0.1 & - \\
\hline \multirow[t]{3}{*}{ S3 } & $0-20$ & 7.8 & 1.78 & 42 & 1.50 & 79 & 22 & 24 & 210 & - & 0.6 & 0.3 & 0.2 & -1.6 & -1.5 & 0.2 & - \\
\hline & $20-40$ & 7.6 & 2.14 & 33 & 1.13 & 52 & 20 & 22 & 132 & - & 0.2 & -0.1 & -0.4 & -1.7 & -1.6 & -0.5 & - \\
\hline & $40-60$ & 7.7 & 1.69 & 24 & 0.90 & 41 & 28 & 33 & 94 & - & -0.2 & -0.4 & -0.8 & -1.2 & -1.1 & -1.0 & - \\
\hline \multirow[t]{3}{*}{ S4 } & $0-20$ & 7.7 & 4.86 & 63 & 1.17 & 78 & 23 & 24 & 258 & - & 1.1 & -0.1 & 0.1 & -1.5 & -1.5 & 0.4 & - \\
\hline & $20-40$ & 7.9 & 1.06 & 37 & 0.93 & 131 & 19 & 22 & 111 & - & 0.4 & -0.4 & 0.9 & -1.8 & -1.6 & -0.8 & - \\
\hline & $40-60$ & 7.9 & 1.44 & 25 & 1.03 & 47 & 36 & 33 & 96 & - & -0.2 & -0.2 & -0.6 & -0.8 & -1.1 & -1.0 & - \\
\hline \multirow[t]{3}{*}{ S5 } & $0-20$ & 7.8 & 1.6 & 35 & 1.27 & 119 & 17 & 19 & 222 & - & 0.3 & 0.1 & 0.8 & -1.9 & -1.9 & 0.2 & - \\
\hline & $20-40$ & 8.0 & 0.98 & 26 & 1.33 & 101 & 18 & 22 & 169 & - & -0.1 & 0.1 & 0.5 & -1.8 & -1.6 & -0.2 & - \\
\hline & $40-60$ & 7.9 & 1.1 & 29 & 1.60 & 109 & 25 & 31 & 176 & - & 0.0 & 0.4 & 0.6 & -1.4 & -1.2 & -0.1 & - \\
\hline \multirow[t]{3}{*}{ S6 } & $0-20$ & 7.9 & 1.2 & 28 & 1.67 & 91 & 31 & 39 & 115 & - & 0.0 & 0.5 & 0.4 & -1.1 & -0.8 & -0.7 & - \\
\hline & $20-40$ & 7.9 & 1.17 & 24 & 1.47 & 51 & 37 & 53 & 87 & - & -0.2 & 0.3 & -0.5 & -0.8 & -0.4 & -1.1 & - \\
\hline & $40-60$ & 7.9 & 1.3 & 26 & 1.40 & 38 & 40 & 59 & 95 & - & -0.1 & 0.2 & -0.9 & -0.7 & -0.2 & -1.0 & - \\
\hline \multirow[t]{3}{*}{ S7 } & $0-20$ & 7.6 & 4.81 & 31 & 2.13 & 88 & 32 & 32 & 86 & 1589 & 0.1 & 0.8 & 0.3 & -1.0 & -1.1 & -1.1 & 1.2 \\
\hline & $20-40$ & 8.1 & 1.00 & 22 & 2.65 & 52 & 31 & 29 & 34 & 851 & -0.4 & 1.1 & -0.4 & -1.1 & -1.3 & -2.5 & 0.3 \\
\hline & $40-60$ & 8.0 & 1.86 & 21 & 2.73 & 55 & 34 & 29 & 27 & 523 & -0.4 & 1.2 & -0.4 & -0.9 & -1.3 & -2.8 & -0.4 \\
\hline S8 & $0-20$ & 7.7 & 2.04 & 19 & 0.81 & 47 & 43 & 46 & 126 & 472 & - & - & - & - & - & - & - \\
\hline
\end{tabular}

graphically. The distance of each site to site $\mathrm{S} 0$ is also represented.

\section{Discussion}

\subsection{Presence of PCB in the catchment and relation to anthropogenic sources}

PCBs can be transported long distances and are among the most widespread environmental pollutants, having been detected in almost every corner of the globe (UNEP 1999). Background level in the study area (measured at S8) was $0.47 \mathrm{ng} \mathrm{g}^{-1}$ (dry weight). Comparison with other background values is not straightforward, because of the different congeners analyzed in different studies. Even so, background levels found in this study were of the same order of magnitude of the PCB background signal in rural soils (IA, USA), which is $0.35 \mathrm{ng} \mathrm{g}^{-1} \mathrm{dw}$ (USEPA 2007a). The trace amounts of PCB measured at $\mathrm{S} 8$ are likely air transported and deposited on site.
This is the prevailing theory for the appearance of trace amounts of PCB in remote areas worldwide (USEPA 2007a).

Given the effective adsorption of PCB to soils and sediments, these contaminants can also be transported bound to eroded soil and sediments. PCB levels in two sampling sites of the Loreto Catchment were ten times higher at site $\mathrm{S} 0$ and three times higher at site S7, compared to background level (S8). According to geo-accumulation index, site $\mathrm{S} 0$ is moderately to highly polluted and site S7 is moderately polluted, indicating that PCBs are still present in the catchment, even though PCB production was banned in the late 1970s. The study area has a big high-to-medium voltage transformer station and numerous medium-to-low voltage transformer substations for electricity supply of households, services and industry. These electric utilities use dielectic fluids (oils), which probably still contain PCB. Oil leakage to soil from electric utilities during regular operation has been identified as a PCB source to the environment, so it is likely that emissions to soil are also occurring at the study site. PCBs are hydrophobic, so PCBs leaked to the soil are transported together with particulate material to the lower levels of the catchment, where they 
Fig. 2 Sampling sites S0, S7 and S8 and corresponding PCB levels at three depths (for S8 only, the top layer was sampled)

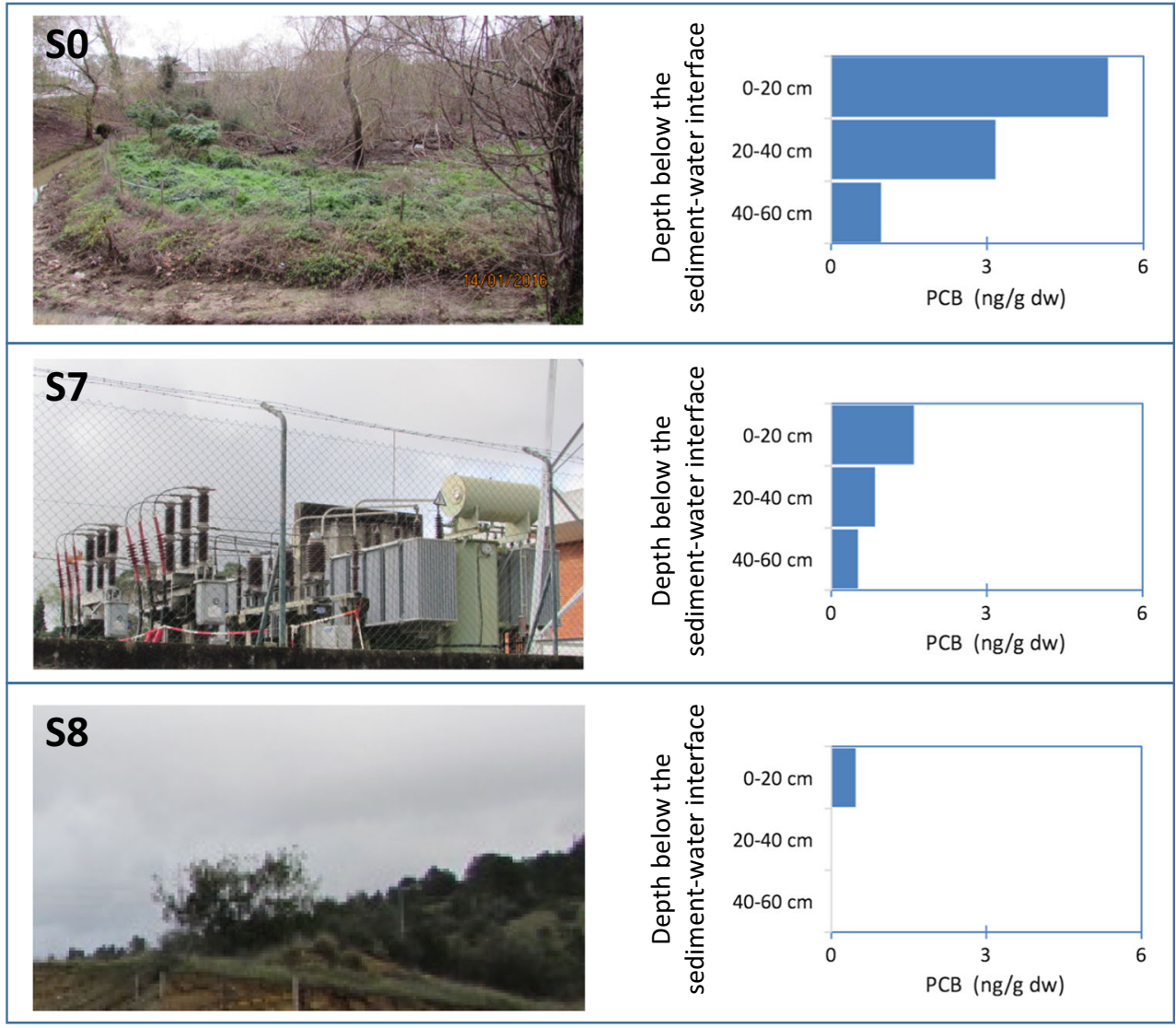

accumulate together with sediments. This can explain the high PCB levels measured at accumulation site S0. The PCBs found in soil samples collected downstream of the large electric power-transforming station (S7) also suggest that the electrical facility is a point source of PCB in the catchment.

The relative percentage of $\mathrm{PCB}$ congeners at each location (Fig. 3) shows a difference between background sample (S8) and sampling sites S0 and S7. It can be seen that for the

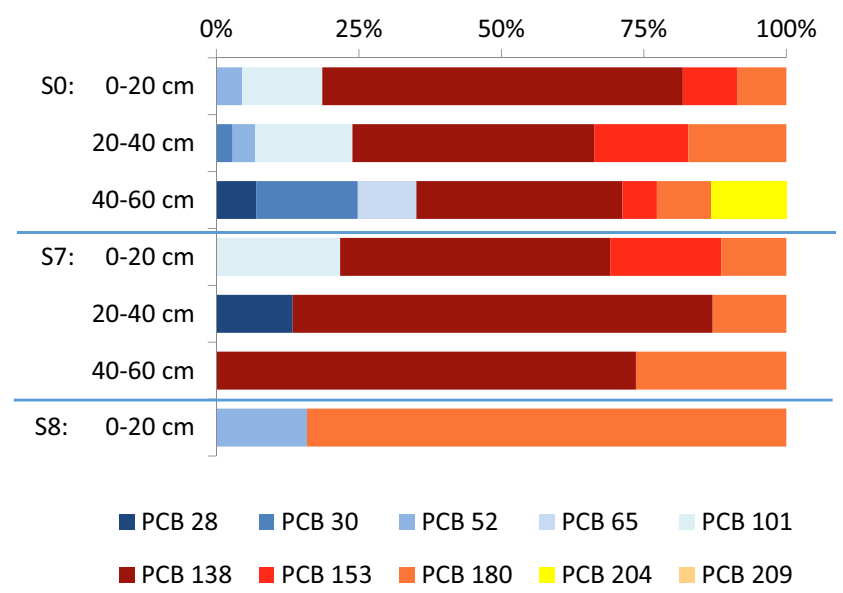

Fig. 3 PCB profiles for the ten congeners analyzed (\% of total PCB mass) in samples from the Loreto catchment: S0 and S7 (three depths $0-20,20-40$ and $40-60 \mathrm{~cm}$ below the surface or below the watersediment interface) and S8 (0-20 cm below the surface) background sample, approximately $85 \%$ is PCB180 and $15 \%$ is PCB52. In samples collected from S0 and S7, there is a dominance of hexachlorobiphenyls, especially PCB138. Both the higher PCB levels in S7 and S0, as well as the distinct congener profile when compared to background values, suggest the presence of local sources of PCB in the catchment, in addition to the long-distance, air-transported PCB.

\subsection{Vertical PCB profiles}

PCB levels in the Loreto catchment increase from the bottom to the top layers (Fig. 2), and the higher levels in the top layer suggest a continued release to the environment until recent times, likely from PCB-containing old electric equipment in the electrical utilities present in the catchment. PCBs were manufactured since the 1920s, and their use becomes widely spread in the following decades, until they were banned in the late 1970s. Our findings are consistent with other works which refer that neither increase nor reduction in the input of PCBs has occurred during the past 20 years in the Upper Mississippi River catchment (Martinez et al. 2016).

Considering that PCB production started in 1920s and that there are no known natural sources of these compounds, the presence of PCBs in the deepest sediment layer $(40-60 \mathrm{~cm}$ in depth) suggests that the sediment column is 100 years old. 


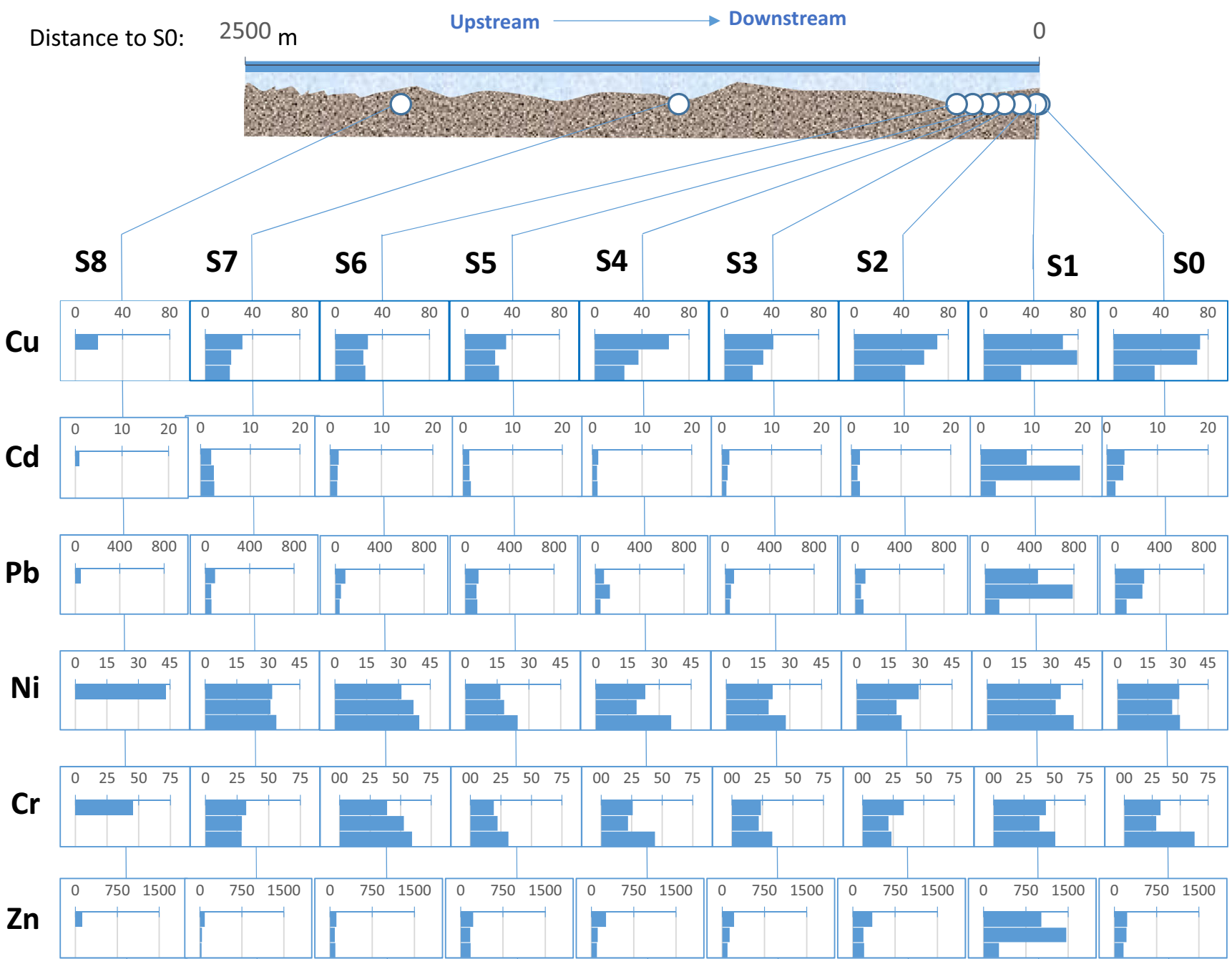

Fig. 4 Heavy metal concentration $\left(\mathrm{mg} \mathrm{kg}^{-1} \mathrm{dw}\right)$ at three depths $(0-20 ; 20-40 \mathrm{~cm} ; 40-60 \mathrm{~cm})$ and along longitudinal profiles of Loreto Stream (S8-S0)

A difference in the congener profiles with depth can be seen between sampling sites S0 and S7 (Fig. 3). At S0, the congener profiles are similar for different depths, suggesting that little ageing of PCB and few losses have occurred in the sediments. Under normal conditions, PCBs are slow to degrade, and higher chlorinated congeners (those with five or more chlorine atoms) are especially resistant to biodegradation. On the contrary, at site S7, there is an elevated contribution of higher-molecular-weight congeners in the deeper layer, which may result from the loss of the less chlorinated congeners by solubilization or volatilization, as suggested by Manz et al. (2001). These differences are likely related to differences in the site's water regime, with site $\mathrm{S} 0$ being saturated during long periods, whilst site $\mathrm{S} 7$ being well above the water table.

\subsection{Spatial variability of heavy metals and relation to anthropogenic sources}

Nickel and chromium are found throughout the sampling sites at background levels (I-geo $\leq 0$ ). On the contrary, copper, zinc, lead and cadmium have generally higher concentrations.
Geo-accumulation index indicates $\mathrm{S} 0$ as being moderately polluted $(1<\mathrm{I}$-geo $<2)$ because of elevated $\mathrm{Cu}, \mathrm{Cd}$ and $\mathrm{Pb}$ levels. As mentioned above, this site is representative of alluvial sediment deposition, where contaminated particulate material from across the catchment becomes concentrated over time.

Sampling site S1 shows the highest levels of pollution $(3<$ I-geo $<4$ ), being highly polluted for $\mathrm{Cd}, \mathrm{Pb}$ and $\mathrm{Zn}$ and moderately polluted for $\mathrm{Cu}(2<\mathrm{I}$-geo $<3)$. When moving $50 \mathrm{~m}$ upstream (S2-S7), metal levels approached background levels for the catchment (except for a slight increase in $\mathrm{Cd}$ at sampling site $\mathrm{S} 7$ and in $\mathrm{Cu}$ at sampling sites $\mathrm{S} 2$ and $\mathrm{S} 4$ ). This behaviour suggests that the pollution source responsible of $\mathrm{Zn}$, $\mathrm{Pb}$ and $\mathrm{Cd}$ was very near to point $\mathrm{S} 1$ and that its impact was very localized (less than 50-m radius).

Close to S1, there are only two possible metal sources. One is a ceramic factory ("Lufapo") (unknown opening date), which went bankrupt in the economic crisis of 1929, being sold to another ceramic company in 1930 . The new owner made huge investments in this facility immediately after 
acquisition, building five new ovens. This factory was later closed in 1980s. The second possible source is an important national road, which, until the early 1990s, was the main north-south axis connecting Lisbon and Oporto and which crossed Coimbra very close to sampling site S1. According to Hjortenkrans et al. (2008), the levels of heavy metals resulting from emissions from vehicle traffic decrease exponentially with distance to the road, with metal concentrations reaching regional background levels only after $5-10 \mathrm{~m}$. This indicates a rather limited metal-affected area around roads, which is consistent with our results.

$\mathrm{Zn}, \mathrm{Pb}$ and $\mathrm{Cd}$ have also a distinct vertical profile at $\mathrm{S} 1$ (Fig. 4), with very low levels at the deepest layer $(40-60 \mathrm{~cm})$ and highest levels at the intermediate layer $(20-40 \mathrm{~cm})$. The upper layer shows a decrease in metal levels, compared to the intermediate layer. This profile suggests that in the last 100 years, there was an initial period of low emissions, followed by a period with increased emissions. In more recent times, the pollution levels decreased again. Given the similarity in the vertical profile, it is likely that all three metals have the same main pollution source. Copper also presents a similar profile in sampling site S1, even though the differences between the layers are not as sharp as for $\mathrm{Zn}, \mathrm{Pb}$ and $\mathrm{Cd}$, being attenuated for this metal.

$\mathrm{Pb}$ was used as additive in petrol from the 1920s till the beginning of 2000, when the European legislation discontinued its use. Given the high levels of $\mathrm{Pb}$ found at $\mathrm{S} 1$ (up to almost $800 \mathrm{mg} \mathrm{kg}^{-1}$, I-geo $=4$ in the intermediate sediment layer) and its vertical and horizontal distribution, we assume that the predominant source for $\mathrm{Pb}$ was most probably the national road. $\mathrm{Pb}, \mathrm{Zn}$ and $\mathrm{Cu}$ are the most common heavy metals emitted by vehicle traffic, totalling at least $90 \%$ from the total emitted quantity (USEPA 2007b). Vehicle traffic is also responsible for the emission of some small quantities of Cd (USEPA 2007b, Ferreira et al. 2016a).

This information together with the similarity of the profiles of $\mathrm{Pb}, \mathrm{Zn}, \mathrm{Cu}$ and $\mathrm{Cd}$ suggest that road traffic is the common main historic source to all four metals at sampling site S1. The reduction from the intermediate to the top layer is not as accentuated for $\mathrm{Cu}$ as for the remaining metals $(\mathrm{Pb}, \mathrm{Zn}, \mathrm{Cd})$, suggesting new inputs in recent times from other source(s). This new input is also seen in other sampling sites across the catchment, where an enrichment of $\mathrm{Cu}$ is seen at the top layer (e.g. at sampling sites S2 and S4). This is not unexpected considering that copper is used in numerous anthropogenic activities and consequently accumulates in the soil (TrujilloGonzález et al. 2016).

In a multi-elemental fingerprint for road traffic emissions (Hjortenkrans et al. 2006, 2008), the covariation between concentrations of different traffic-related metals in roadside soils allowed to identify metal groups and couple each group to vehicle traffic sources. Two groups of metals were identified in which the correlation was strong: the $\mathrm{Cd}$ and $\mathrm{Pb}$ group, representing elements where historical emissions have been most important, and the $\mathrm{Cu}, \mathrm{Sn}$ and $\mathrm{Zn}$ group, which is associated to braking, that is wearing of tyre and breaking lines during braking (Hjortenkrans et al. 2006, 2008). In another work, a high correlation was also found for $\mathrm{Ni}, \mathrm{Cu}, \mathrm{Cr}$ and $\mathrm{Zn}$ in road dusts (Trujillo-González et al. 2016). This later study shows that road impacts depend on the type of road considered, with metal contents in road dust being higher in commercial areas than in highways and higher in highways than in residential roads.

These associations explain the presence of $\mathrm{Cd}, \mathrm{Pb}, \mathrm{Cu}$ and $\mathrm{Zn}$ in sampling site $\mathrm{S} 1$ and its distinct behaviour from other sampling points, corroborating the hypothesis that the national road was the main historical source for these four metals.

\subsection{Comparison of contaminant levels in the catchment against quality criteria guidelines}

According to the quality criteria in Table 1, sampling sites S7 and S8 were classified as "not contaminated" (class 1), while site is classified as class 2 "trace contamination", with respect to PCB levels.

From the six metal elements analyzed, three of them $(\mathrm{Cd}$, $\mathrm{Pb}$ and $\mathrm{Zn}$ ) had levels that placed them in the range of slight to heavy contamination (class 3 to class 5) of the dredged material classification. These higher values occurred in sampling sites S0 and S1, with S1 being the only site with "heavy contamination". For the other three metals $(\mathrm{Ni}, \mathrm{Cr}$ and $\mathrm{Cu})$, the levels found across the catchment are generally higher than the "lowest effect level" but within class 1 or 2 ("clean" or trace contamination). These results are in line with the I-geo values (see Table 3 and discussed in the previous sections).

According to Portuguese quality criteria sample from S8, used as background reference for the catchment, ranked either class 1 (clean) or class 2 (trace contamination) for all target metal contaminants, the same occurred for sampling sites S2 to S7.

\subsection{Impact of contaminant levels for the management of the catchment}

The results obtained and discussed above (Sects. 4.1, 4.2, 4.3 and 4.4) indicate that sampling site $\mathrm{S} 1$ is the most contaminated, especially due to the presence of cadmium, lead and zinc. This contamination has been associated to the presence of a national road. Site S0, representative of an alluvial sediment deposition near the mouth of the catchment, is also contaminated. The levels here are thought to be due to the accumulation along time of the pollutants emitted across the catchment and which are transported with particulate material, becoming concentrated in this area. All other sampling sites analyzed are clean or present at most only trace levels of contamination. 
Since concentrations decrease rapidly with the distance to sampling sites S0 and S1, the strategy suggested to deal with this contamination problem is to define a buffer area around these two sites, where construction is restricted. The sediment accumulation area (S0) is problematic in terms of floods, and it is currently an abandoned area. Even though abandonment makes sense since it prevents contact with the population, we do recommend some active management by the competent authorities, for instance, the installation of a small urban woodland. Given the level of contaminants, we would recommend that access to this woodland is interdict to the urban population (as it is at the moment, the area is of difficult access, although no information exists on the risks for human health), as there is the risk of contact (and consequently ingestion or inhalation) of contaminated particulate material. Furthermore, any use of the space for agriculture or to grow any type of products that may enter the food chain or be in close contact with humans should be actively forbidden. In fact, in a previous study (Roy and Donald 2015), it was found that consumption of carrot and lettuce grown in soils contaminated with a variety of metals including lead, zinc, cadmium and copper has the potential to cause toxicological problems in men, women and young children resulting from $\mathrm{Cd}$ and $\mathrm{Zn}$ accumulation. The woodland would thus serve the purpose of promoting urban biodiversity, not human leisure nor agricultural purposes. In addition, $\mathrm{S} 0$ is an area prone to occasional flooding, so there is also the risk of transport of accumulated sediment and respective contaminants to the major river Mondego. The impacts to the aquatic ecosystem are not evaluated but can be significant, as highlighted in the introduction for a different case study, so it would be important to implement effective sediment traps. Integrated measures comprising the use of vegetation buffers, storage dams and the establishment of riparian vegetation along small streams within catchment are in line with previous suggestions from other researchers (Mekonnen et al. 2015).

The removal and cleansing of the soil are not, at the moment, a viable solution given the wide area that should be recovered and the associated costs. The more practical solution is to interdict any use other than renature for biodiversity, in the municipal urban management plan, that has legal strength (equivalent to a law) to enforce the renature of contaminated areas and knock down any other abusive land use that might endanger human health.

Regular sampling should be performed to assess the fade of pollutants, prior to any other use of these contaminated areas, namely recreational usages.

\section{Conclusions}

Within the urban catchment of Loreto, geo-accumulation index for PCB shows site S0 (a downstream sediment accumulation area) as being moderately to highly polluted and site S7, near the electric utility (point source for PCB), as moderately polluted. Higher levels in the top layer suggested a continued input until recent times, likely from continued leakage from the high-to-medium voltage electric utility and several medium-to-low voltage substations located across the catchment. Nonetheless, quality levels according to Portuguese legislation were not exceeded and the sediments/soil was classified either as class 1 (not contaminated) or class 2 (trace contamination) with respect to PCB.

From the six metal elements analyzed, three $(\mathrm{Cd}, \mathrm{Pb}$ and $\mathrm{Zn}$ ) showed elevated concentrations at site S1, along with a distinct profile with depth, which have been associated to vehicle traffic emission. In addition, site S0, where contaminated particulate material from across the catchment is concentrated over time, was found to be moderately polluted because of elevated $\mathrm{Cu}, \mathrm{Cd}$ and $\mathrm{Pb}$ levels $(1<\mathrm{I}$-geo $<2)$.

The results show the presence of PCB and heavy metal pollution in the Loreto Catchment up to present times, even though for PCB, a ban occurred in the late 1970s and the emission source of metal no longer exists at that location. The work highlights that the impact of pollution from historic sources within the catchment can be extended to present time. In case of floods or construction works (such as building parks and leisure zones), these pollutants now buried in the sediments might surface and be redistributed, impacting the downstream ecosystem of the major Mondego River or increasing the risk of exposure of the urban population. Given that the level of contaminants sharply decreases as one moves away from these sites, a risk management strategy would be to define a buffer area around these contaminated sites where a small urban woodland could be installed. This way, urban biodiversity would be promoted while preventing contact with human urban populations. In these cases, the Municipal Urban Management Plans (that, in Portugal, are equivalent to a Law) must restrict the use and even the access to these areas, and regular sampling should be made to evaluate pollutant fade over time.

Acknowledgments This work has been funded by the European Regional Development Fund (ERDF) through COMPETEOperational Programme for Competitiveness Factors (OPCF), by Portuguese national funds through "Fundação para a Ciência e a Tecnologia (FCT)" under projects PTDC/AGR-AAM/101643/2008 and UID/AMB/00681/2013. C. Dias-Ferreira gratefully acknowledges Fundação para a Ciência e para a Tecnologia (FCT) for financial support (SFRH/BPD/100717/2014).

\section{References}

ATSDR (2000) Toxicological profile for polychlorinated biphenyls (PCBs). Atlanta, GA: U.S. Department of Health and Human Services, Public Health Service, Agency for Toxic Substances and Disease Registry 
ATSDR (2016) Priority list of hazardous substances. Agency for Toxic Substances \& Disease Registry. http://www.atsdr.cdc.gov/spl/. Accessed 29 January 2016

Cachada A, Lopes LV, Hursthouse AS, Biasioli M, Grcman H, Otabbong E, Davidson CM, Duarte AC (2009) The variability of polychlorinated biphenyls levels in urban soils from five European cities. Environ Pollut 157:511-518

Desmet M, Mourier B, Mahler BJ, Van Metre PC, Roux G, Persat H, Lefèvre I, et al. (2012) Spatial and temporal trends in PCBs in sediment along the lower Rhône River, France. Sci Total Environ 433:189-197

DR (1995) Diário da República No 141/95, II Série - Despacho Conjunto de 21 Junho de 1995. pp. 6805-6807 (in Portuguese)

Ferreira AJD, Soares D, Serrano LMV, Walsh RPD, Dias-Ferreira C, Ferreira CSS (2016a) Roads as sources of heavy metals in urban areas. The Covões catchment experiment, Coimbra, Portugal. J Soils Sediments. doi:10.1007/s11368-016-1492-4

Ferreira CSS, Walsh RPD, Costa ML, Coelho COA, Ferreira AJD (2016b) Dynamics of surface water quality driven by distinct urbanization patterns and storms in a Portuguese peri-urban catchment. J Soils Sediments. doi:10.1007/s11368-016-1423-4

Gomes HI, Ottosen LM, Ribeiro AB, Dias-Ferreira C (2015) Treatment of a suspension of PCB contaminated soil using iron nanoparticles and electric current. J Environ Manag 151:550-555

Guan Q, Wang L, Pan B, Guan W, Sun X, Cai A (2016) Distribution features and controls of heavy metals in surface sediments from the riverbed of the Ningxia-Inner Mongolian reaches, Yellow River, China. Chemosphere 144:29-42

Guo G, Wu F, Xie F, Zhang R (2012) Spatial distribution and pollution assessment of heavy metals in urban soils from southwest China. J Environ Sci 24:410-418

Hjortenkrans D, Bergbäck B, Häggerud A (2006) New metal emission patterns in road traffic environment. Environ Monit Assess 117:85-98

Hjortenkrans DST, Bergbäck BG, Häggerud AV (2008) Transversal immission patterns and leachability of heavy metals in road side soils. J Environ Monitor 10:739-746

ISO (1995) Soil quality - extraction of trace elements soluble in aqua regia (ISO 11466:1995(E). First edition, Genève, Switzerland. $6 \mathrm{p}$

ISO (1998) Soil quality — determination of cadmium, chromium, cobalt, copper, lead, manganese, nickel and zinc in aqua regia extracts of soil-Flame and electrothermal atomic spectrometric methods - ISO 11047:1998(E). First edition, Genève, Switzerland. $18 \mathrm{p}$

Kachenko AG, Singh B (2006) Heavy metals contamination in vegetables grown in urban and metal smelter contaminated sites in Australia. Water Air Soil Pollut 169:101-123

Lee CSL, Li X, Shi W, Cheung SCN, Thornton I (2006) Metal contamination in urban, suburban, and country park soils of Hong Kong: a study based on GIS and multivariate statistics. Sci Total Environ 356:45-61

LQARS (1977) Sector de Fertilidade do Solo. Laboratório Químico Agrícola Rebelo da Silva. DGSA-Ministério da Agricultura, Lisboa 39 pp (in Portuguese)
Manta DS, Angelone M, Bellanca A, Neri R, Sprovieri M (2002) Heavy metals in urban soils: a case study from the city of Palermo (Sicily), Italy. Sci Total Environ 300:229-243

Manz M, Wenzel KD, Dietze U, Schurmann G (2001) Persistent organic pollutants in agricultural soils of central Germany. Sci Total Environ 27:187-198

Martinez A, Erdman NR, Rodenburg ZL, Eastling PM, Hornbuckle KC (2012) Spatial distribution of chlordanes and PCB congeners in soil in Cedar Rapids. Environ Pollut 161:222-228

Martinez A, Schnoebelen DJ, Hornbuckle KC (2016) Polychlorinated biphenyl congeners in sediment cores from the Upper Mississippi River. Chemosphere 144:1943-1949

MEE (1997) Guideline for use at contaminated sites in Ontario. Ministry of Environment and Energy, Ontario ISBN 0-7778-6114-3

Mekonnen M, Keesstra SD, Stroosnijder L, Baartman JEM, Maroulis J (2015) Soil conservation through sediment trapping: a review. Land Degrad Develop 26(6):544-556

Rodrigues SM, Cruz N, Coelho C, Henriques B, Carvalho L, Duarte AC, Pereira E, Römkens PF (2013) Risk assessment for $\mathrm{Cd}, \mathrm{Cu}, \mathrm{Pb}$ and $\mathrm{Zn}$ in urban soils: chemical availability as the central concept. Environ Pollut 183:234-242

Roy M, McDonald LM (2015) Metal uptake in plants and health risk assessments in metal-contaminated smelter soils. Land Degrad Develop 26:785-792

Sandahl JF, Baldwin DH, Jenkins JJ, Scholz NL (2007) A sensory system at the interface between urban stormwater runoff and salmon survival. Environ Sci Technol 41:2998-3004

Shafie NA, Aris AZ, Haris H (2014) Geoaccumulation and distribution of heavy metals in the urban river sediment. Int J Sediment Res 29: 368-377

Tavares AO (1999) Physical constraints to planning. Susceptibility analysis in the Municipality of Coimbra. PhD Thesis. University of Coimbra. 346 pp (in Portuguese)

Tchounwou PB, Yedjou CG, Patlolla AK, Sutton DJ (2012) Heavy metal toxicity and the environment. In Molecular, clinical and environmental toxicology, Springer Basel, pp 133-164

Trujillo-González JM, Torres-Mora MA, Keesstra S, Brevik EC, Jiménez-Ballesta R (2016) Heavy metal accumulation related to population density in road dust samples taken from urban sites under different land uses. Sci Total Environ 553:636-642

UNEP (1999) Guidelines for the identification of PCBs and materials containing PCBs. United Nations Environmental Programme, August 1999

USEPA (2007a) Pilot Survey of levels of polychlorinated dibenzo-pdioxins (PCDDs), polychlorinated dibenzofurans (PCDFs), polychlorinated biphenyls (PCB) and mercury in rural soils of the U.S., Washington, DC

USEPA (2007b) Metals risk assessment, United States Office of Air Quality, EPA 120/R-07/001, 3-21-29

Zhang Z, Juying L, Mamat Z (2016) Sources identification and pollution evaluation of heavy metals in the surface sediments of Bortala River, Northwest China. Ecotoxic Environ Safe 126:94-101 